\title{
Politics, Disability Governance and Inclusiveness of Parasport Athletes in a Coronavirus Pandemic Aftermath in Africa: Observations from Nigeria
}

\author{
P.T.I. Okudolo ${ }^{1,2}$ and V. Ojakorotu ${ }^{2, *}$ \\ ${ }^{1}$ Postdoctoral Research Fellow in African Studies, Indigenous Language Media in Africa (ILMA) Entity, North \\ West University (NWU), Mafikeng, South Africa \\ ${ }^{2}$ Department of Political Studies and International Relations, Faculty of Humanities, North West University, \\ Mafikeng, South Africa
}

\begin{abstract}
The paper evaluates politics and governance underlining disability inclusion development using reflections in parasport. Its thesis-of-thesis derives from the presentation of surveyed explanations from Nigerian stakeholders in the Paralympics sector to generalize for Africa. Before the COVID-19 pandemic outbreak, politics in Africa shows an abysmal scorecard in terms of combating discrimination against disabled persons. Accordingly, the continent's disability inclusiveness governance shows it is effectual. Thus, there is perhaps ample indication to adduce that sports politics will continually fail to achieve the inclusiveness of parasports athletes in a coronavirus epidemic aftermath. Using the Nigerian context, the paper gathers evidence from interviews with stakeholders and evaluative-secondary data in parasports concerning not only to responding to disability inclusion in sports but also to the wider politics of sustaining inclusiveness of Paralympic athletes in a post-COVID-19 era. The paper argues that the character of politics in Africa generally has not resulted in optimal investments, considerations, and willpower from political leaders to advance outcomes in the aspect of inclusivity of athletes with disabilities. It considers contextual factors that militate against achieving all-inclusiveness of disabled sports persons and how politics can be channelled to achieve their optimum wellbeing in the sports arena.
\end{abstract}

Keywords: Sports politics, Paralympic athletes, social inclusion, coronavirus/COVID-19, disability governance, Nigeria.

\section{INTRODUCTION}

In the literature, disability inclusion refers to how society orders the life and living of disabled people. A very important view of the discourse applies to the social structuring of how disabled persons partake and function in the entire process of society's development. Those who engage this topic mostly diagnose how public social, economic, and political policies afford people with disabilities as the other diverse able citizens to enjoy their existence subject to each person's capacities, limits and wants. The question of why disability continues to be a stigma in Africa seems to inspire a quite unpleasant answer naturally, whereas such unpalatable responses ought not to be the case considering the global push to make living worthwhile even for being disabled [1, 2]. Empirically, the African response implies that disability-inclusive development is still farfetched from the global expectation [3].

However, there is increasing worldwide awareness for advancing inclusive disability development administration policies, as well as more needed selfreflection on national programme actions to evolve

*Address correspondence to this author at the Department of Political Studies and International Relations, Faculty of Humanities, North West University, Mafikeng, South Africa; Tel: 018 3892259; E-mail: Victor.Ojakorotu@nwu.ac.za better disability-inclusiveness in all spheres of life, especially in sports. At the international organizational spaces, the United Nations (UN) Charter and its core principles and valuations envision a disability-inclusion stratagem that supports the attainment of the UN Convention on the Rights of Persons with Disabilities. The UN proviso for disability inclusion aims to facilitate the realization of all international human rights regimes for their inclusivity in line with the Sustainable Development Goals. Also, according to the Protocol to the African Charter on Human and Peoples' Rights on the Rights of Persons with Disabilities in Africa, people with disabilities have inalienable human rights and dignities that should be protected, safeguarded, and sustained in the continent and by her numerous intergovernmental public policy infrastructures as enshrined in the African Union Protocol, adopted January 29, 2018. Findings from studies $[4,5]$ suggest that a conscious global effort towards domestication of the UN, $A U$, and every other supranational organizations' protocol and charter on disability inclusion persist state-qua-state.

The paper argues that from the viewpoint of a growing global consciousness to advance the governance of disablism concerns to come at par and be equitable to the normal government actions to 
promote good governance on a continental scale. Enthusiasm for achieving this inclusiveness in sports should not be disregarded but tinkered with as it remains an unresolved issue in Africa [6,7]. The paper presents the view that realizing disability inclusiveness in African socio-political, economic, and every other space of public life must-have elements of cognition and political will. That is, a consciousness that should be inherent in public decision-makers, and in the game of politics itself must exist. And this mindfulness must be geared towards the pursuit of purposeful power and authority to determine favourable outputs and outcomes of the inclusion process of disabled members of society.

The rest part of this paper is dedicated to expounding the abovementioned objectives. This will be done under sections that diagnose these themes: first is a conceptual clarification of key terms of our discourse; next is a brief background of disability governance focusing on Africa; then the summary of the methods for data matters are espoused, including the analyzed research questions; next is the presentation of results from the analysis of the survey and secondary data; then is the summarizing of the findings; and lastly is the conclusion which highlights some recommendations that need to be considered to actualize an inclusive society for the disabled member of African societies viewed through parasports.

\section{CONCEPTUAL CLARIFICATIONS}

It is important to stress from the outset that the paper adopts both nominal and operational definitions to avoid terminological ambiguity. Some of the terms used in the literature will suffice, while some others need to be operationalized. For this paper and its purpose, concepts such as politics of sports and disability inclusion governance particularly will be operationalized.

\section{Social Inclusivity/Inclusiveness/Inclusion}

Expectedly, in any discussion on promoting inclusivity into society, the mental understanding of what works optimally for all (i.e., the able and disabledbodied of the women, men, and male/female children gender, and maybe it is wise to include the LGBT community) must be present-speaking to questions like whether a particular design of walkway or car park works for all categories? Or how to construct the stairways such that it also serves the disabled? Answering these kinds of mental questions that exercise the brain underscore a consciousness towards society's inclusiveness, particularly for individuals with physical incapacities. According to a 2015 Singapore Management University Centre for Management Practices view [8], for inclusivity to materialize into society, "there must be an awareness for diversity and inclusion...' so that you don't just have a very homogenous group of people making the decision'". Generally, an inclusive society is understood as one in which governance is exerted to guarantee equal opening for all to persists regardless of disabilities. So that all can achieve their full potential because the conditions that allow active involvement of both able and disabled members of society in all facets of life, including sports, are present. As well as that special-persons enjoy chances to actively partake in the decision-making processes to establish the enabling conditions for inclusive society to exist [9].

\section{Politics of Sports}

Parrish [10] notes that politics of sports or sports politics is as regards to using sports to advance a range of other policy objectives such as progressing social inclusion. By contextual implication, the term references David Easton's often-quoted definition of politics as the "authoritative allocation of value" [11] as so deployed by policymakers to advance sports' social benefits beyond its domain to other public affairs in, for instance, disability inclusivity purposes. Ordinarily to the paper, politics of sports refers to the prevailing organizational and institutional structures and established systems, processes, and practices to handle the administration, development, and governance of sport. Operationalized herein, the concept is inclined to realpolitik (for more on the notion of sports' realpolitik or realpolitik in sports (see McCrory [12]. Sports' realpolitik is the concrete expressions, tussles, struggles, and conflicts of interests, values, and powers that constitute a barrier or impede social disability inclusion or otherwise in the sports terrain. Contextually, therefore, sports politics or the politics of sports is indicative of norms, institutions, socio-political relations, and processes that should promote the participation of Paralympic athletes on the basis of equivalence of human rights, social justice, impartiality, fairness, and self-esteem in sports causing them to feel inclusion.

Sports governance, politics of sports, realpolitik in sports, and sports politics may be interchangeably used in the paper. Empirically, abled-bodied sports federations have tended to express and exercise 
control more over politics and governance of special sports activities than exact, disabled kind of sports establishments. The dominance by the abled-bodied sports federations still persists in some parasports despite the inauguration of the International Sports Organization for the Disabled (ISOD) in 1964. For example, Wheelchair tennis standards are set by the abled-bodied International Tennis Federation; rules for disabled table tennis are governed by the International Table Tennis Federation; disabled rowing sport is controlled by the International Rowing Federation, and the International Canoe Federation sets the standards for special athletes in canoe sport. Para-athletes in boccia also abide by the rules set by the abled-bodied Boccia International Sports Federation. The struggles against the dominance of the governance and politics of disability sports by the abled-bodied sports organizations and the pursuit of parasports' autonomy have been on for years, but it gained impetus in 1993. It was non-inclusion of disability sports in the regular International Olympic Committee (IOC) agenda in 1993, which then after power was transferred to the International Paralympic Committee (IPC) to assume governance of the Paralympics Games that year.

According to Alla and Ajibua [13], the context of sports politics, governance, and administration of sports in Nigeria typifies an order from aboveobedience from below top-down model of power configuration. This is whereby elected leaders at the top decide for the athletes below the ladder of power. And this top-down model stratagem in sports governance has universal appeal in the sense that almost all countries adopt it. Overwhelming power usually lies with the political leaders at the executive arm of government transcending downwards. Similarly, the top-down power flow also exists at the state level too, in which the governor's office determines the pattern of sports administration of the state.

In Nigeria, the National Sports Council (now renamed National Sports Commission [NSC] in 1984), a federal government agency, sits atop the politics, governance, and administration of sports [13]. The functions of the NSC as revised in Act No. 34, 1984, inter alia: a) To encourage the development and organization of and participation in sports in Nigeria; b) To coordinate and integrate efforts to raise the standards of performance in sports through Nigeria; and d) To promote co-operation with other sports bodies sports groups, the physical fitness and general well-being of all persons in Nigeria (sic. with emphasis on the well-being of disabled persons). Organogram- wise, appointment cum directives descend from the President downwards the Minister of Sports/Chairman NSC, to the NSC Governing Board appointed by the President, and then to the NSC Director General who presides over and is assisted by Directors of admin, and finance, training and research, sports organizing/coaching, and medical centre. At the Nigerian state government level, the top-down order of politics, governance, and sports administration is as follows: Governor > Commission for Sports > DirectorGeneral of the state's Sports Commission > Secretaries to the various State's Sports Associations.

What is to be noted from the ensuing discussion is that the structural configuration of sports governance and administration of Nigeria - which is very similar for other African countries - is bound to have dialectical repercussions on the politics of parasports. It is this aforesaid thinking about politics of sports that derives from the said discussions that cause the paper to explore this hypothetical assumption: The dynamics, dimensions, and dialectics of disability-inclusive development in the African special sports sector may be said not to be developing as expected due to abysmal commitments by abled-bodied elected and appointed public officials to actually establish inclusivity, as well as that the dominance of disabled sportspersons in the politics, governance, and decision-making for Paralympic sports does not actually foster the disabled persons' inclusiveness.

\section{Disability Inclusion Governance}

A situation of disability exclusion into society implies the obvious absence of capacity, power, or acknowledgement of the disabled-bodied and their lack of a sense of belongingness, inclusion, recognition, voice, and legitimacy to participate in the inclusionbuilding process fully. The grounds for exclusion or marginalization could be based on gender, age, ethnicity, sex, cultural/traditional belief, religion, economic cum social class, or more to our context one's disabilities [9]. Thus, operationally speaking, disability inclusion governance is conceived as government officials' developmental decision actions, processes, and activities throughout the policymaking circle of embedding inclusiveness of disabled persons into society. This requires conscious entrenchment of active involvement and full participation of the disabledbodied members of society in the political processes leading to authorizing policies and shaping practices to actualize disability inclusion. In accordance with the United Nations Convention on the Rights of Persons 
with Disability; the 2015 Singapore Management University Centre for Management Practices [8]; the African Charter on Human and Peoples' Rights on the Rights of Persons with Disabilities in Africa; and the South Africa Integrated National Disability Strategy White Paper (view online: https://www.independentliving.org/docs5/SANatIDisStrat1.html), as well as [14], a disability inclusion governance process that does not cause increased participation in socially expected roles of the disable-bodied person in society is nothing more than advancing exclusionary trends.

\section{Disability Versus Ability}

Disability underscores the existence of physical, psychological, or mental limitations such as blindness (impairment of vision), upper (arm) and lower (leg) amputee, deafness (hard to hear), autism disorders, mentally unhealthy conditions, intellectually disabled, etc. Hence, ability underlines the absence of the abovementioned human limitations. To this context, disabilities that take part in competitive sports (i.e., Paralympics) are amputees, the vision impaired, cerebral palsy patients, Les Autres (locomotor disabilities), intellectually impaired, spinal cord injuries, and the deaf. The International Paralympic Committee (IPC) defines disability as "...the degree of activity limitation resulting from the impairment," and this enables the sports association to set standards of participation in competitive sports for disabled persons [15]. It is to be noted that special persons, parasport athletes, or Paralympic athletes can be inter-used for disabled persons in the paper.

\section{Coronavirus/COVID-19 Pandemic Aftermath}

The novel coronavirus disease (patented as SARSCoV-2), also popularly known as COVID-19, is a pandemic allegedly emerged from Wuhan, China. As at July 15, 2020, Worldometer statistics on the global dimension of the coronavirus is: COVID-19 cases- 13 , 520, 403; deaths- 582, 672; recovered- 7, 902, 235; active cases- 5, 035, 496; and closed cases$8,484,907$. The stats further show that of the active cases, 4, 975, 988 (i.e., 99\%) were mild condition, while 59, 508 (i.e., 1\%) were serious or critical. The closed cases show that 7, 902, 235 (i.e., 93\%) recovered/discharged, while 582, 672 (i.e., $7 \%$ ) reflects deaths (source: https://www.worldometers.info/ coronavirus/?utm_campaign=homeAdvegas 1?). What the statistics mentioned above accentuate is that there is yet no cure for the pandemic. Thus, in operationalizing the notion of coronavirus/COVID-19 pandemic aftermath, we imply the presence of a vaccine or cure, but not that coronavirus has been exterminated from existence. That is, the concept, as used in the paper, implies life after a cure or vaccine from the pandemic is in the public space but not necessarily that the virus does not exist again. This means that the coronavirus aftermath indicates the disease does not constitute a pandemic. By implication, not that people will still not be affected or exposed to the coronavirus in the pandemic's aftermath but that the virus no more assumes a pandemic status.

\section{Explanatory Briefs on the African Context of Disability Inclusion Development}

In spite of much attention to disability concerns globally, unfortunately, the olden time view whereby able persons conceive of disability as a burden to others; as something to be pitied or punishment from divinity for one form of transgression is still popular in Africa [7]. This is despite the UN declaration far back in 1981 as the Year of the Disabled Persons, which signifies part of a universal commitment to achieve social justice and eradicate exclusion of the disabledbodied in society. Harknett [16] has proffered some determinism models to explain how Africans view disability: 1, medical/health determinism, which suggests that disability is a result of intake of modern orthodox Western countries' medicine, especially like family planning medications; 2 , traditional spiritism cum animism determinism which suggests disability is a product of witchery, wizardry, enchantment or reprimand from the cultural gods; 3, Allah (Islam)/Yahweh (Christian) determinism which suggests that disability stems from the will of Allah/God on adherents of the belief. We add the fourth, being Ingstad's [17] view of mixed-notion determinism, which suggests that disability can be explained by combining the determinisms mentioned above, such as proffering both traditional spiritism and a Christian/Islam belief to explain the cause of disability.

The prevalence of belief in Africa about disability is not in keeping with the global push to pursue the inclusion of the disabled members of the African community. Hence, [3: 154] has noted that the African disability inclusion project transited from the Organization of African Unity (OAU) to the African Union (AU) haven established the premise of Africa's backwardness in terms of disability inclusiveness since its inauguration in 1963. Following several meetings of the OAU Council of Ministers and its ancillary organs in the 1980s, provision for disability rights was enshrined 
into the OAU's legal corpus. Article 18(4) of the African Charter on Human and People's Rights (ACHPR) says: "The aged and the disabled shall also have the right to special measures of protection in keeping with their physical and moral needs". However, according to [3], this disability clause in the ACHPR legalistic corpus did not cater for the basis of discrimination against special persons.

Furtherance of disability inclusion in Africa saw the $\mathrm{AU}$ enact and adopt several protocols to achieve the inclusiveness of disabled persons. One such was the 2007 espousal of the African Charter on Democracy, Election and Governance (ACDEG), which came into force in 2012. Article 8(2) of the ACDEG provides that: States Parties shall adopt legislative and administrative measures to guarantee the rights of the marginalized and vulnerable social groups, including people with disabilities. Again, an AU ordinance which came into force in 2012 arising from the 2009 AU Convention held in Kampala, Uganda, enshrined in 9(2)(c) that: State parties shall provide for special protection for and assistance to internally displaced persons with special needs, including persons with disabilities. These articles underscore a renewed drive on the part of African politics to eliminate the social exclusion of her disabled persons. But, despite these and other ordinances on disability inclusion of the AU, Oyaro's view cited from [3: 158)] criticism holds sway:

...Despite the provisions on disability, the African treaties adopt a rudimentary medical model approach to disability that singularly attributes disability to impairment without considering social and environmental factors. Using phrases such as "handicapped children" and "mentally and physically challenged youths" demonstrate this. Therefore, it is not surprising that the provisions vindicate solutions relating to "special care" and "special measures of protection" almost to exclude inherent rights. In this way, existing African regional instruments on disability fall short of international human rights standards as prescribed in the CRPD that adopt a more social, rightsbased approach to disability.

In the light of the above quote, Donohue and Bornman [18] argue that a major problem of instituting full disability inclusivity in Africa relates to the poor governmental implementation of the AU protocols on disability inclusion. Secondly, the authors note that "the apparent lack of clarity in the policy, i.e., ambiguity about the goals for inclusion and the means through which they can be achieved" [18: 1] constitute another critical problem of establishing inclusiveness in Africa. Elekwe [19] study suggests that the failure of the Nigerian government viz African states to inadequately domesticate and judiciously implement these domesticated policies for inclusion of citizens with disabilities is at the heart of the continuing exclusion of disabled persons, and this seems to reverberate across Africa. In the arena of sports, Mauerberg-deCastro, Campbell, and Tavares [20] suggest that the problem of leadership and governance of parasports whereby elite Paralympic sportsmen/women are not appointed into decision-making administrative positions constitutes a drawback to the development of inclusiveness in sports. The authors mentioned leadership in parasports by elite Paralympic athletes is common in advanced economies like Germany, USA, China, and Australia, among others, but no African country was listed. By deductive reasoning, the study of Patatas, Bosscher, Derom, et al. [21] links the complex national-state-local intergovernmental relations system, cultural practices, and the sociopolitical environment context of Africa like her politics and governance of sports, parasport administration and a dominated political culture by abled-persons generally as important factors that otherwise influence advances in disabled-sports inclusion.

\section{RESEARCH DESIGN}

\section{Methodology}

In the view of Bryman, Bell, Hirschsohn, et al. [22:5], asking questions and getting answers through survey research goes a long way to help understand the goings-on within a sector like gauging inclusivity in parasports. Thus [22] believes that sampling views of stakeholders within an organizational setting on an issue through discussions do help provide a better appreciation of norms, practices, and realities of the sector. Accordingly, this paper's methodological orientation is a qualitative epistemology because its data derives from analyses of views, impressions, observations, and interpretations of happenings by key stakeholders in the Nigeria parasports sector. According to Patatas, Bosscher, and Legg [23], the qualitative inclined research method has proven to be highly valuable in measuring parasports athletes' needs, wants, and desires. 
Qualitative epistemology has to do with constructing knowledge, understanding, and impressions from interviews, discussions, observations, and narrations or contents of written, audio, or visual materials. This means that qualitative data are derived from interviews, descriptions of observed occurrences, group conversation/discussion, published written/printed works, movies/television programmes, and radio programmes/audio messages.

To expound on the paper earlier stated hypothetical assumption, two objectives vis-à-vis research questions were formulated. The formulated research objectives and questions are:

\section{Objective}

To understand the views, impressions, and beliefs of some stakeholders in the Nigerian sports sector on disability-inclusive development in the country's parasport before and during this coronavirus pandemic.

\section{Question}

What views, impressions, and beliefs do some stakeholders in the Nigerian sports sector have of the country's disability inclusion development before and during this COVID-19 pandemic period?

\section{Objective}

To construe reform measures from the gathered qualitative data on how to strengthen the inclusivity development project of Nigerian parasport athletes in sports of the country generally in a coronavirus pandemic aftermath.

\section{Question}

What reform measures need to be established to strengthen the inclusivity development of Nigerian parasport athletes in sports generally of the country in COVID-19 pandemic aftermath?

\section{Sampling of Participants}

A purposive stakeholder-requirement-definition sampling technique (see [24]) is most suitable to provide useful data on a special discourse such as ours. This sampling method emphasizes engaging active participants in the unique sector, such as our discussion of sports governance and politics, and as they relate to the inclusivity of para-athletes. Hence, participants in the study were purposively selected.
This means the participants included other stakeholders apart from para-athletes. The sampling process is based on choosing those with profound familiarity and involvement in the parasports inclusivity development project of Nigeria. Other criteria for sampling include (i) have over three years of active involvement in the parasports sector of Nigeria; (ii) have appreciable workings of the sports politics and governance of parasports in the understudied country; (iii) voluntary consent is given to contribute in providing data.

From the table below, the first letters of the names of the ten (10) participants make-up their code name. Six male and four female participants partook in the discussions. Of the participants, two were parasports coaches, and another two are sports journalists with the News Agency of Nigeria (NAN) on Sports Desk. The other six participants are highly experienced paraathletes that have made their mark in terms of experience and laurels in parasports. It is important to stress that Table 1 indicates that all the participants meet the criteria for the researchers' sampling set.

\section{Data Gathering Procedure}

According to Bhattacherjee [25], a credible data collection process will likely cause research findings to be valid and reliable. Thus, the validity and reliability of data vis-à-vis the question under examination have an important linkage to the procedure through which data was collected. The data gathering for the paper consists of multiple sources linked to qualitative epistemology.

Firstly, data derived from news reports of the participants who are journalists with the parasport athlete-participants and coach-participants. This constituted the evaluative-secondary data source. The analyzed news reports were purposively selected by the journalist-participants based on their correlation with the thematic codes. Secondly, the researchers held discussions/conversations with the coachparticipants and the journalist-participants. Two sets of discussions/conversations were held. One was with the journalist-participants and the other with the coachparticipants via telephone. The third qualitative epistemological source of data gathering for the paper was interviews with the parasport athlete-participants. This was done in two stages: face-to-face interviews through the journalist-participants and telephone interviews with the researchers/authors of the paper. By implication, the two journalist-participants doubled 
Table 1: Demographic Representation of Participants

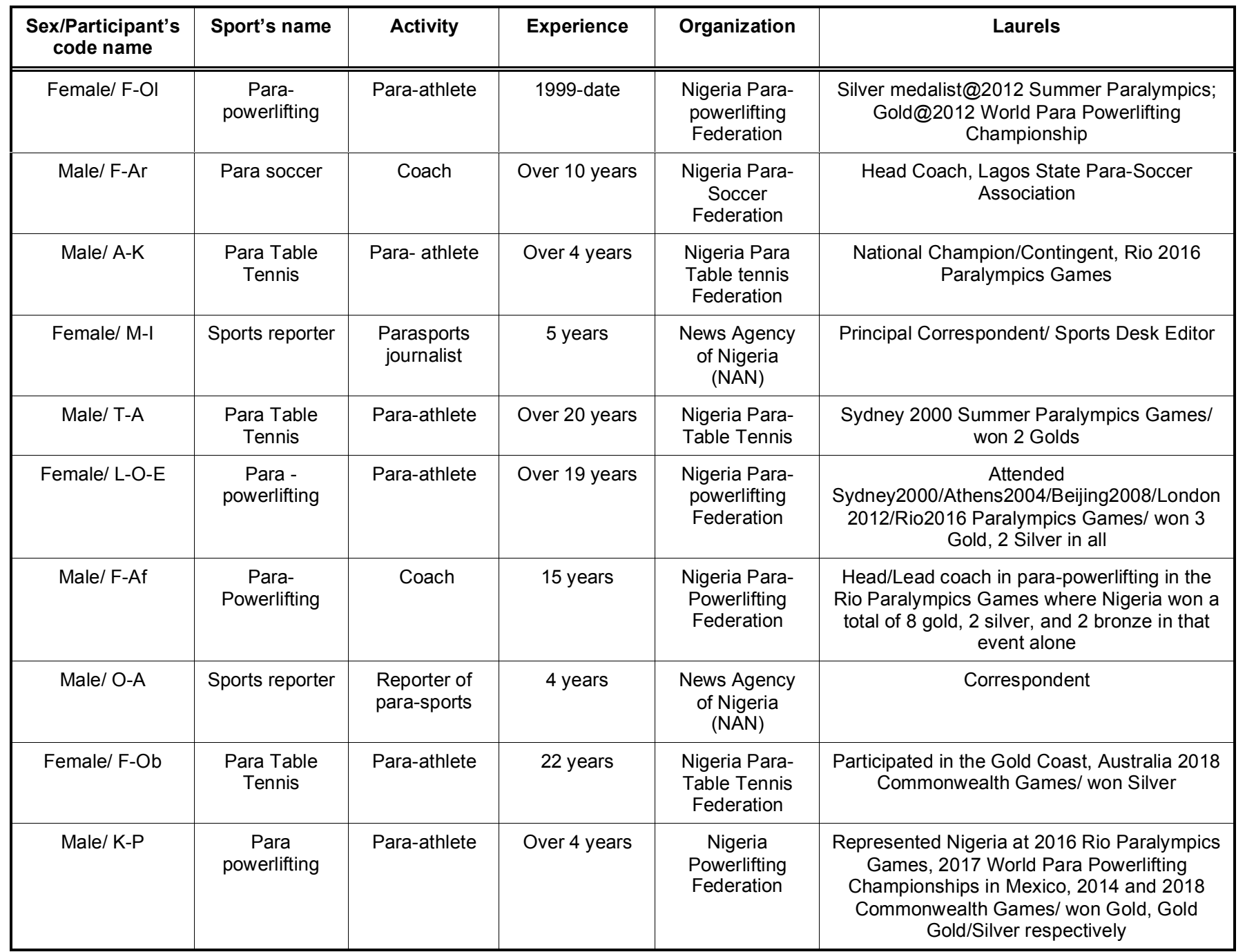

as employed research assistants as well as participants that provided data to help realize the set objectives of the paper.

The open-ended semi-structured questioning approach was adopted in the interviews, discussions, and conversations to collect data. According to Newcomer, Hatry, and Wholey [26], this approach to data collection in qualitative epistemology allows interviewees greater latitude to be interactive, more comfortable, freer, friendlier, and highly disposed to engage the interview questions. It, as well as has high prospects to make interviewees reveal information they otherwise might not easily do under a closed-ended structured questioning environment. It is to be noted that all ethical considerations with gathering data for this paper were adhered to. Such as consent to engage the participants as well as utilize the secondary data were granted.

\section{Analysis Method of Collected Data}

The thematic content analysis approach to data scrutiny is usually the commonest way of analyzing information derived from studies with a qualitative epistemological orientation [27]. The process of analyzing the contents of qualitative epistemologically derived data entails extrapolating interpretation and understanding from a set of given data in relation to deduced thematic codes [28]. From the outset, thematic codes were deduced from the early stage of casting the title and reasoning out the keywords of the paper. The themes were acknowledged by their evolving patterns, as is obviously connected with the paper's focus. Our themes did not evolve from a specific theoretical consideration or from the collected data or extant literature on the subject-matter under examination. We generated the themes following Ryan and Bernard's [29] sketched pattern in line with the 
strengthening of validity and reliability of findings. Hence, the authors' assumed thesis-of-thesis, which elicited the paper in the first place as captured in the paper's title and keywords, produced the thematic codes. These themes are: sports politics and governance in Nigeria, disability inclusion governance in parasports before and during coronavirus pandemic, and post COVID-19 pandemic aftermath parasport governance cum politics.

\section{RESULTS AND DISCUSSION}

\section{Sports Politics and Governance in Nigeria}

Participants generally described the politics and governance of parasports activities in Nigeria as lagging behind advanced countries. They noted that the patterns of "the authoritative allocation of values" were not strong enough to give the impression that parasports activities could be treated like crude oil extraction or healthcare. One of the participants, O-A, said, "sports are still being relegated in the overall scheme of politics in the country". They generally felt that parasports sector, in particular, was worse-off in terms of needed attention by political leaders at the federal and state levels. T-A said, "my local government council has never done anything to support me. It is like the council feels catering for paraathletes is the job of the state and federal governments alone." According to one of M-l's news report, the Nigerian parasports sector still suffers from inadequate governmental investment at all levels. The first sentence in an online news report of Timothy Obiezu entitled: Nigeria's Disabled Athletes Face Surprising Challenges published online on September 20, 2019, says, "Nigeria's Paralympic athletes have outshined their able-bodied counterparts in world competitions year after year. Yet, these athletes face such challenges as lack of proper training facilities and inadequate funding." This aptly illustrates that words of F-Ar who said "more public funds need to be budgeted for para-athletes to make them be the best in the world." For some participants, administration of parasports has not truly been a source of a morale booster to the athletes mostly. F-Ob articulated this by saying, "many times I laugh at the treatment we get from the stadium officials during training."

\section{Disability Inclusion Governance in Parasports before and during Coronavirus Pandemic}

Participants generally noted that inclusivity in Nigerian parasports activities has not to cause self- sufficiency to para-athletes before the COVID-19 pandemic outbreak. They felt existing infrastructure for parasports and the various programmes to develop the athletes have not really been gratifying. L-O-E articulated this view by saying, "as long as we paraathletes are not vested with the real power to shape our destiny...we can't say we feel fully and totally included." One of the para-athlete participants (F-Oi) said, "although my federation is being headed by one of us, but the real power to make a decision he shares with the able-bodied". According to the Guardian Sport online report of May 11, 2019, entitled: U.S. Sports Envoy Mentor Nigerian Paralympic Athletes, Coaches, Nigeria requires capacity development in managing parasports as well as the need to imbibe best practices in para-athletes inclusivity development projects in Paralympics. K-P went on to say that "where experienced para-athletes are abundant in a sport, they should be given more leadership role than the ablebodied secretaries/administrators." Likewise, F-Af noted that "up till now, existing infrastructure such as toilets and bathrooms are still not suited for most parasports athletes in Nigeria." All the participants did not speak with much hope that para-athletes were likely to enjoy necessary attention during the coronavirus pandemic outbreak. In fact, A-K said, "before now, we still experience some discrimination in treatment, I should not feel things will suddenly change." In the view of Okon [30], disability inclusivity in Nigeria will not happen until the country takes disability issues as an integral aspect of growth in her economic, social and political spheres. For example, the complaints about poor appreciation from governments, corporate organizations, and even the public, as well as abysmal compensation of medalwinning Nigerian Paralympians, do not align with Adamu's [31] definition of inclusive growth as "broad progression and all-encompassing advancement". The complaints/ feeling of exclusion vis-à-vis assessment of Nigeria's inclusivity development in sports is captured thus by Okon [30:15], that a functional inclusion development is such that will lead to "a sustainable gainful livelihood is essential for ensuring individuals with disabilities are economically empowered, can fulfil their basic needs and contribute financially to their families, communities and society at large."

\section{Post COVID-19 Pandemic Aftermath Parasport Governance Cum Politics}

A number of participants framed their expectations for parasport- athletes' inclusion in the aftermath of coronavirus. For example, A-K said, "the need to 
provide infrastructure for disabled athletes such as functional toilets, car park spaces for disabled persons and special healthcare unit where we train is necessary." Similarly, K-P said, "government must go beyond providing us with facemasks and hand sanitizers where we train, but increase our number in the governing boards." Participants stressed the importance of inclusive involvement of para-athletes in the politics and governance of their sports. M-I noted that the inclusion of parasport athletes in decisionmaking would raise their sense of belongingness, which is needed to cope during and after the COVID19. F-Oi articulated this by saying, "when I see a disabled-person as a coach and team leader at any international tourney I am participating in, it gives me hope that the world is beginning to recognize we have much to offer." The study of Wareham, Burkett, Innes, and Lovell [32] found that despite misconceptions about the ability of disabled persons and preconceived stigma of disabilities, the retention rate of elite paraathletes as coaches in Australia was higher than for abled-bodied sports. The finding of Wareham et al. is countered by F-Ob in the Nigerian experience by saying, "disabled elite athletes should not have to ask, bribe or play politics to be retained to guide upcoming ones and lead their sporting activities." Another participant, O-A, said, "the experienced para-athletes ones should be sponsored on international coaching courses, seminars and training programmes for them to take the lead of their sports." To the coach participants, improvements in everybody's medical/health insurance in Nigeria's parasport sector, whether federal or state levels, is a sacrosanct necessity in COVID-19 pandemic aftermath. By and large, participants were skeptical that nothing substantial in the area of disability sports inclusivity in Nigeria after the coronavirus pandemic will occur in parasports if the political leaders don't commit to that goal. As Okon [30: 15] has noted that a sustainable, successful inclusivity development in Nigeria cannot have inclusive growth unless the disable-bodied is made a fundamental part of the planning, policy formulation, and authorization as well as in the policy implementation processes.

\section{CONCLUSION}

The result and discussion section of the paper calls attention to the ineffectual disability inclusion in Nigeria's parasports, thereby echoing an African-wide similarity as the context of the understudied location is a barometer of the situation of the continent. The data speak to a sense of disenchantment with whatever is on the ground in terms of disability inclusion governance and sports politics before and during the coronavirus pandemic. Furthermore, the paper's results are indicative of an abysmal sense of commitment by political leaders to ensure disable-bodied athletes with requisite experience, skills, and competencies superintend the politics, governance, and administration, and also actively partake in the decision-making of their sporting area. In Africa, the stereotypical impressions about disability can only be eradicated if there is political will invested in the direction of realpolitik in sports. The definitive goal of disability inclusion in sports in the continent cannot, therefore, be fruitful and sustainable, except it is achieved through well-thought-out, inclusively formulated public policies. This will thus require committed able-bodied to commit to the optimum entrenchment of disability-inclusive development into society, working hand in hand as equals with knowledgeable disabled-persons to persist.

\section{REFERENCES}

[1] Michailakis D. Ability, inability, disability, and antidiscrimination law. Scandinavian Journal of Disability Research 2000; 2(2): 32-62. https://doi.org/10.1080/15017410009510759

[2] Salmonsson A. Disability is not inability: A baseline study of the steps taken towards inclusive education in Blantyre, Balaka and Machinga Districts in Malawi. Publication of the Sweden Institute of Public Management 2005.

[3] Appiagyei-Atua K. A comparative analysis of the United Nations Convention on the Rights of Persons with Disability and the African Draft Protocol on the Rights of Persons with Disability. Law, Democracy and Development 2017; 21: 153175.

https://doi.org/10.4314/ldd.v21i1.8

[4] Lord JE, Stein MA. The domestic incorporation of human rights law and the United Nations Convention on the Rights of Persons with Disability. Washington Law Review 2008; 83: 449-480.

https://doi.org/10.2139/ssrn.1551945

[5] Viljoen F, Biegon J. The feasibility and desirability of an African disability rights treaty: Further norm-elaboration or firmer-norm implementation. South African Journal on Human Rights 2014; 30(2): 345-365.

https://doi.org/10.1080/19962126.2014.11865112

[6] Lang R, Schneider M, Kett M, Cole E, Groce N. Policy development: An analysis of disability inclusion in a selection of African Union policies. Development Policy Review, 2017; 37: 155-157. https://doi.org/10.1111/dpr.12323

[7] Swartz L, Bantjes J, Knight B, Wilmot G, Derman W. 'They don't know we exist': South African participants in competitive disability sport and the politics of identity. Disability and Rehabilitation 2016. https://doi.org/10.1080/09638288.2016.1242171

[8] Singapore Management University Centre for Management Practices. Working inclusiveness into society. Publication of the Centre for Management Practice, Singapore Management University 2015.

[9] United Nations- Department of Economic and Social Affairs (DESA). Creating an inclusive society: Practical strategies to promote social integration. DESA Draft Document 2009. 
[10] Parrish R. The politics of sports regulation in the European Union. Journal of European Public Policy 2003; 10(2): 246262. https://doi.org/10.1080/1350176032000059026

[11] Gabriel JM, David Easton's 'authoritative value allocation': Activating the definition's potential 2017. https://doi.org/10.2139/ssrn.2909910

[12] McCrory P. Research realpolitik. British Journal of Sports Medicine 2002; 36(1): 1-5. https://doi.org/10.1136/bjsm.36.1.1

[13] Alla JB, Ajibua MA. Administration of physical education and sports in Nigeria. Higher Education Studies 2012; 2(1): 8896. https://doi.org/10.5539/hes.v2n1p88

[14] Ferri BA, Connor DJ. Tools of exclusion: Race, disability, and (re)segregated education. Teachers College Record 2005; 107(3): pp. 453-474.

https://doi.org/10.1111/j.1467-9620.2005.00483.x

[15] Beacom A, Brittain I. Public diplomacy and the International Paralympic Committee: Reconciling the roles of disability advocate and sports regulator. Diplomacy and Statecraft 2016; 27(2): 273-294.

https://doi.org/10.1080/09592296.2016.1169795

[16] Harknett SG. Cultural factors in the definition of disability: A community study in Nyankunde, Zaire. African Journal of Special Needs Education 1996; 1: 18-24.

[17] Ingstad B. Mpho ya modimo- A gift from God: Perspective on 'attitude' towards disabled persons. B. Ingstad, SR Whyte eds. Disability and culture. Berkley, CA: University of California 1995.

[18] Donohue D, Bornman J. The challenge of realizing inclusive education in South Africa. South African Journal of Education 2014; 34(2): 1-14. https://doi.org/10.15700/201412071114

[19] Elekwe CJ. A review of the challenges of achieving the goals in the African Plan of Action for people with disabilities in Nigeria. Disability and Society 2013; 28(3): pp. 313-323. https://doi.org/10.1080/09687599.2012.710009

[20] Mauerberg-deCastro E, Campbell DF, Tavares CP. The global reality of the Paralympic movement: Challenges and opportunities in disability sports. Motriz: Revista de Educacao Fisica 2016. https://doi.org/10.1590/S1980-6574201600030001

[21] Patatas JM, Bosscher VD, Derom I. Rycke JD. Managing parasport: An investigation of sports policy factors and stakeholders influencing para-athletes' career pathways. Sports Management Review, 2019. https://doi.org/10.1016/j.smr.2019.12.004
[22] Bryman A, Bell E, Hirschsohn P, Du Toit J, Dos Santos A, Wagner C, Van Aardt I, Masenge A. Research methodology: Business and management contexts $5^{\text {th }}$ ed. Cape Town, SA: Oxford Press, 2014.

[23] Patatas JM, Bosscher VD, Legg D. Understanding parasports: An analysis of the differences between abledbodied and parasport from a sports policy perspective. International Journal of Sport Policy and Politics 2018; 10(2). https://doi.org/10.1080/19406940.2017.1359649

[24] Smith AR, Colombi JM, Wirthlin JR. Rapid development: A content analysis comparison of literature and purposive sampling of rapid reaction project. Procedia Computer Science 2013; 16: 475-482. https://doi.org/10.1016/j.procs.2013.01.050

[25] Bhattacherjee A. Social science research: Principles, methods, and practices $2^{\text {nd }}$ ed. 2012.

[26] Newcomer KE, Hatry HP, Wholey JS. Handbook of practical program evaluation $4^{\text {th }}$ ed. New Jersey: John Wiley and Sons, 2015.

https://doi.org/10.1002/9781119171386

[27] Vaismoradi M, Turunen $\mathrm{H}$, Bondas $\mathrm{T}$. Content analysis and thematic analysis: Implications for conducting a qualitative descriptive study. Wiley Online Library, 2013. https://doi.org/10.1111/nhs.12048

[28] Vaismoradi M, Jones J, Turunen $H$, Snelgrove S. Theme development in qualitative content analysis and thematic analysis. Journal of Nursing Education and Practice 2016; 6(5): 100-110. https://doi.org/10.5430/jnep.v6n5p100

[29] Ryan GW, Bernard HR. Techniques to identify themes. Fields Methods 2003; 15(1): 85-109. https://doi.org/10.1177/1525822X02239569

[30] Okon EO. The path to inclusive growth in Nigeria: Are people with disabilities carried along? American Economic and Social Review 2018; 2(1), pp. 6-19. Published by the Centre for Research on Islamic Banking and Finance and Business. https://doi.org/10.46281/aesr.v2i1.150

[31] Adamu MM. Delivering inclusive growth for economic development in Nigeria. International Journal of Entrepreneurial Development, Education and Science Research 2017; 4(1): 209-217.

[32] Wareham Y, Burkett B, Innes P, Lovell GP. Coaches of elite athletes with disability: Senior sports administrators' reported factors affecting coaches' recruitment and retention. Qualitative Research in Sport, Exercise and Health 2018; 11(3): pp. 398-415. https://doi.org/10.1080/2159676X.2018.1517388

\section{https://doi.org/10.6000/2292-2598.2021.09.01.1}

(C) 2021 Okudolo and Ojakorotu; Licensee Lifescience Global.

This is an open access article licensed under the terms of the Creative Commons Attribution Non-Commercial License (http://creativecommons.org/licenses/by-nc/3.0/) which permits unrestricted, non-commercial use, distribution and reproduction in any medium, provided the work is properly cited. 